\title{
Mechanical ventilation enhances extrapulmonary sepsis-induced lung injury: role of WISP1-av 35 integrin pathway in TLR4-mediated inflammation and injury
}

Xibing Ding ${ }^{1,3,5,6+}$, Yao Tong ${ }^{1 \dagger}$, Shuqing Jin ${ }^{1,3}$, Zhixia Chen ${ }^{1}$, Tunliang Li ${ }^{2,3}$, Timothy R. Billiar ${ }^{3}$, Bruce R. Pitt ${ }^{4}$, Quan $\mathrm{Li}^{1,7^{*}}$ and Li-Ming Zhang ${ }^{5^{*}}$

\begin{abstract}
Background: High tidal volume ventilation of healthy lungs or exacerbation of existing acute lung injury (ALI) by more moderate mechanical ventilation (MTV) produces ventilator-induced lung injury. It is less clear whether extrapulmonary sepsis sensitizes the lung to MTV.

Methods: We used a two-hit model of cecal ligation and puncture (CLP) followed $12 \mathrm{~h}$ later by MTV (10 ml/kg; $6 \mathrm{~h})$ to determine whether otherwise noninjurious MTV enhances CLP-induced ALI by contrasting wildtype and TLR4 ${ }^{-/}$mice with respect to: alveolar-capillary permeability, histopathology and intrapulmonary levels of WNT-inducible secreted protein 1 (WISP1) and integrin $\beta 5$; plasma levels of cytokines and chemokines (TNF-a, IL-6, MIP-2, MCP-1) and intrapulmonary neutrophil infiltration; and other inflammatory signaling via intrapulmonary activation of JNK, p38 and ERK. A separate cohort of mice was pretreated with intratracheal neutralizing antibodies to WISP1, integrin $\beta 5$ or lgG as control and the presented phenotyping repeated in a two-hit model; there were 10 mice per group in these first three experiments. Also, isolated peritoneal macrophages (PM) from wildtype and $\mathrm{TLR}^{-/-},{\mathrm{MyD} 88^{-/-}}$and $\mathrm{TRIF}^{-/-}$mice were used to identify a WISP1-TLR4-integrin $\beta 5$ pathway; and the requisite role of integrin $\beta 5$ in WISP1-induced cytokine and chemokine production in LPS-primed PM was examined by siRNA treatment.

Results: MTV, that in itself did not cause ALI, exacerbated increases in alveolar-capillary permeability, histopathologic scoring and indices of pulmonary inflammation in mice that previously underwent CLP; the effects of this two-hit model were abrogated in TLR4 ${ }^{-/}$mice. Attendant with these findings was a significant increase in intrapulmonary WISP1 and integrin $\beta 5$ in the two-hit model. Anti-WISP1 or anti-integrin $\beta 5$ antibodies partially inhibited the two-hit phenotype. In PM, activation of TLR4 led to an increase in integrin $\beta 5$ expression that was MyD88 and NF-KB dependent. Recombinant WISP1 increased LPS-induced cytokine release in PM that was inhibited by silencing either TLR4 or integrin $\beta 5$.
\end{abstract}

Conclusions: These data show for the first time that otherwise noninjurious mechanical ventilation can exacerbate ALI due to extrapulmonary sepsis underscoring a potential interactive contribution of common events (sepsis and mechanical ventilation) in critical care, and that a WISP1-TLR4-integrin $\beta 5$ pathway contributes to this phenomenon.

Keywords: Acute lung injury, Integrin, Lipopolysaccharide, Mechanical ventilation, Peritoneal macrophages, Sepsis, Toll-like receptor 4, WISP1

\footnotetext{
* Correspondence: quanligene@126.com; Zhangl1@anes.upmc.edu

${ }^{+}$Xibing Ding and Yao Tong contributed equally to this work.

'Department of Anesthesiology, East Hospital, Tongji University School of

Medicine, 150 Jimo Road, Pudong, Shanghai, China

${ }^{5}$ Department of Anesthesiology, University of Pittsburgh School of Medicine,

200 Lothrop St. UPMC MUH N467, Pittsburgh 15213, PA, USA

Full list of author information is available at the end of the article
}

(c) The Author(s). 2018 Open Access This article is distributed under the terms of the Creative Commons Attribution 4.0 International License (http://creativecommons.org/licenses/by/4.0/), which permits unrestricted use, distribution, and reproduction in any medium, provided you give appropriate credit to the original author(s) and the source, provide a link to the Creative Commons license, and indicate if changes were made. The Creative Commons Public Domain Dedication waiver (http://creativecommons.org/publicdomain/zero/1.0/) applies to the data made available in this article, unless otherwise stated. 


\section{Introduction}

Mechanical ventilation (MV) is well known to cause an iatrogenic syndrome of ventilator-induced lung injury (VILI). The pathophysiology of VILI includes intrapulmonary inflammatory cell infiltrates, increased vascular permeability and pulmonary edema, and it may occur in ventilation of a healthy lung or worsening of preexisting and coexisting injury [1]. Sensitization of VILI secondary to preexisting acute lung injury (ALI) due to pneumonia [2, 3], intratracheal endotoxin [4-7] or sterile injury [8-10] has provided preclinical evidence of a two-hit model.

Although extrapulmonary endotoxemia combined with noninjurious mechanical ventilation leads to VILI $[11,12]$, evidence of such a two-hit phenomenon in experimental extrapulmonary bacterial sepsis is less clear. Ventilating rodents after polymicrobial sepsis due to cecal ligation and puncture (CLP) [13-15] has produced equivocal results regarding sensitization to VILI. Mechanical ventilation with injurious high VT (30-40 ml/kg) exacerbated $48 \mathrm{~h}$ of CLP-induced lung injury in rats [16]; shorter periods of CLP were not associated with subsequent exacerbation of VILI in mice [17] or rats $[9,18]$ although such overall injury was accelerated in the latter. Lower VT $(15-20 \mathrm{ml} / \mathrm{kg})$ did not exacerbate CLP-induced ALI in intact rats [9] or isolated perfused rat lungs [19]. Since both CLP and VILI have a common TLR4-mediated pathway to inflammation and injury $[5,20-22]$ it seems plausible that mechanical ventilation could exacerbate CLP-mediated events within the lung and thus differences are likely to be secondary to variables in experimental protocols (degree of preexisting lung injury, volume and duration of ventilation) as suggested by Yehya et al. [18].

In the current study, we examined the effect of prolonged $(6 \mathrm{~h})$, otherwise noninjurious [4] moderate VT ventilation (MTV) in mice with preexisting mild ALI after CLP (12 h). We focused on a novel WNT1 inducible secreted protein (WISP1 or CCN4; also referred to as WNT1 inducible signaling protein-1)-integrin $\beta 5$ pathway of TLR4-mediated pulmonary inflammation and injury in this two-hit model as we previously noted key roles for WISP1 and beta integrins in VILI [21] and CLP [22, 23] mediated ALI. The mechanism by which WISP1 acts in CLP and/or VILI remains unclear. WISP1 appears, however, to be a modulator of TLR4-CD14 signaling and is known to signal through integrins [24] although the precise integrin is unclear. Although several integrins are important in ALI [25], integrin $\beta 5$ is a central regulator of increased permeability in VILI [26] and CLP [27].

Thus, the overall hypotheses of this study were that: prolonged ventilation with otherwise noninjurious moderate VT exacerbates ALI in extrapulmonary sepsis; WISP1 and integrin $\beta 5$ contribute to this two-hit model (i.e., CLP + MTV); and TLR4 is central to the WISP1TLR4-integrin $\beta 5$ proinflammatory pathway.

\section{Methods}

\section{Experimental protocols}

Animal protocols were approved by the Animal Care and Use Committee and experiments were performed in strict adherence to NIH Guidelines and followed current guidelines for preclinical models in research. Details of materials and methods are provided in Additional file 8: Materials and Methods) and experimental protocols are outlined for intact mice (Additional file 1: Figure S1) and cultured PM (Additional file 2: Figure S2) including: MTV and CLP-induced lung damage via TLR4-dependent, WISP-1 and integrin $\beta 5$ contributory fashion in two-hit lung damage; MTV and CLP-induced changes in circulating levels of cytokines and chemokines, and an association with increased neutrophil infiltration of the lungs of intact mice; other inflammatory signaling (pJNK, p38, pERK) pathways in lungs of mice after CLP and MV; the mechanism of upregulation of integrin $\beta 5$ in LPS-treated PM isolated from wildtype, TLR4 null, $\mathrm{Myd} 88^{-/-}$and $\mathrm{TRIF}^{-/-}$mice; and the requisite role of integrin $\beta 5$ in WISP1-induced cytokine and chemokine production in LPS-primed PM.

\section{In-vivo experimental animal model}

C57BL/6 mice (8-10 weeks old, male) were purchased from Jackson Laboratory and TLR4 ${ }^{-1-}$ mice were used as described previously $[21,22]$. Forty wildtype mice were prospectively randomized to one of four groups $(n=10$ per group): spontaneous breathing (sham control), spontaneous breathing with CLP; mechanical ventilation; or CLP and MTV. Mild sepsis was induced by CLP $[13,14]$ as modified by Ding et al. [23, 28] and MTV $(10 \mathrm{ml} / \mathrm{kg}$; $150 / \mathrm{min}$, zero positive end-expiratory pressure) was performed in anesthetized mice alone or after CLP (12 h). A cohort $(n=20)$ of $\mathrm{TLR}^{-/-}$mice underwent sham and spontaneous breathing ( $n=10$; control) or CLP and MTV as already described $(n=10)$. In separate cohorts, mice were intratracheally administered anti-WISP1 $(n=10)$, anti-integrin $\beta 5(n=10)$ or serum IgG $(n=10 ; 0.5 \mu \mathrm{g} / \mathrm{g}$ in $50 \mu \mathrm{l}$ PBS) after CLP but before MTV. Phenotypic changes due to CLP, MTV or their combination included histopathology (scored by a pathologist blinded to experiments), alveolar-capillary permeability (Evans Blue albumin [21]) and inflammation as assessed by plasma levels of cytokines and chemokines, neutrophil immigration in the lung (flow cytometry) and intrapulmonary MAP kinase activation (phosphorylation status of JNK, ERK and $\mathrm{p} 38$ ).

\section{In-vitro studies}

Isolation and culture of peritoneal macrophages (PM) from wildtype, $\mathrm{TLR}^{-/-}$, MyD88 $8^{-/-}$or $\mathrm{TRiF}^{-/-}$mice was performed as described previously [21, 22]. Cells were treated with LPS and/or costimulated with recombinant 
WISP1 (rWISP1) and cytokine production was assessed in conditioned medium of wildtype cells or after transfection with $50 \mathrm{nM}$ small interfering RNA (siRNA) for integrin $\beta 5$ (sc-35681; Santa Cruz) or scrambled siRNA. The role of TLR4 signaling was assessed by comparing the response of PM isolated from wildtype vs TLR4 ${ }^{-/-}$, $\mathrm{Myd} 88^{-/-}$or $\mathrm{TRIF}^{-/-}$mice.

\section{Histological examination}

Lung tissue samples were fixed in 4\% paraformaldehyde in PBS overnight at $4{ }^{\circ} \mathrm{C}$ and processed as described previously [22] including semiquantitative histopathology (H\&E; light microscopy) by a pathologist blinded to the experimental group.

Western blot analysis of WISP-1 and integrin $\beta 5$ was performed as described previously [21, 22]. Plasma or conditioned medium were assayed for cytokines and chemokines using commercially available ELISA reagents for TNF- $\alpha$, IL-6, MIP-2 and MCP-1.

\section{Flow cytometry}

The lung was enzymatically digested and mechanically dissociated (MACS dissociator) and single cell suspensions were isolated by passing the suspension through a 70- $\mu \mathrm{m}$ filter. Cells were stained with $\mathrm{mAbs}$ specific to Fixable Viability Dye eFluor ${ }^{\circ}$ 506, CD45, CD11b, Ly6G for $30 \mathrm{~min}$ at $4{ }^{\circ} \mathrm{C}$ and fixed with $2 \%$ paraformaldehyde for $10 \mathrm{~min}$ at $4{ }^{\circ} \mathrm{C}$. An LSR II (Becton Dickinson) was used for flow cytometry and data were analyzed with FlowJo software.

\section{Alveolar-capillary permeability}

Evans blue albumin (EBA; 0.5\%, $25 \mathrm{mg} / \mathrm{kg}$ body weight) was injected into the internal jugular vein $1 \mathrm{~h}$ before euthanasia and lung harvesting. Blood samples and lung tissue were obtained and processed as described previously $[21,22]$ and the EBA permeability index was calculated by dividing pulmonary EBA absorbance at $620 \mathrm{~nm} / \mathrm{g}$ of lung tissue by plasma EBA absorbance at $620 \mathrm{~nm}$.

\section{Immunofluorescence staining of cells and florescence microscopy}

PM were cultured for a defined time period, fixed in $4 \%$ paraformaldehyde in PBS for $15 \mathrm{~min}$. Cells were washed in PBS, permeabilized using $0.1 \%$ Triton X-100, blocked with 5\% BSA for $45 \mathrm{~min}$ and sequentially administered primary antibody and secondary antibody (Alexa-488conjugated donkey anti rabbit secondary antibody). Nuclei were stained with DAPI (Thermo Fisher Scientific) and cells were examined and recorded using EVOS FL fluorescence microscopy (immunofluoresence analysis; Thermo Fisher Scientific).
Reagents are described in Additional file 8: Materials and Methods.

\section{Data analysis and statistics}

Data are presented as the mean \pm SEM of the indicated number of experiments and analyzed using one-way and two-way ANOVA; post-hoc testing was performed using the Bonferroni modification of the $t$ test. The individual studies performed throughout this work represent five independent studies. Power analyses were performed by using type I error probability of 0.05 , with a power of 0.9 , to determine the sample size necessary to reject the null hypothesis. All statistical analyses were carried out using the GraphPad Prism 5 program. $P<0.05$ was considered statistically significantly.

\section{Results}

CLP alone led to modest lung injury as demonstrated by histology (Fig. 1a, b) and a significant increase in alveolar-capillary permeability (Fig. 1c, d). MTV alone had no impact on lung injury or permeability, but when applied after CLP it markedly enhanced both the lung injury score and alveolar-capillary permeability. The histopathologic and permeability changes in the two-hit model were completely abrogated in TLR $4^{-/-}$mice and partially (but significantly) reduced in cohorts of mice receiving antibodies to either WISP1 or integrin $\beta 5$. In wildtype mice, we noted that: MTV did not affect intrapulmonary levels of either WISP1 or integrin $\beta 5$; CLP led to small but significant increases in either WISP1 or integrin 35 ; and the two-hit model increased either of these molecules 2-3x more than CLP alone (Fig. 2a, b). We previously noted that high VT ventilation increases in WISP1 were abrogated in TLR4 ${ }^{-/-}$mice [21] and we now note (Fig. 2c) that CLP-induced increases in integrin $\beta 5$ are abrogated in TLR4 ${ }^{-1-}$ mice.

CLP increased circulating cytokines and chemokines whereas MTV alone did not; the combination of MTV and CLP, however, caused levels of all four mediators to progressively rise above levels measured with CLP alone (Fig. 3). Deletion of TLR4 prevented increases in cytokines and chemokines in the two-hit model and inhibition of WISP1 or integrin $\beta 5$ blocked further increases induced by MTV (Fig. 3).

CLP significantly increased neutrophil influx in the lung while MTV had no impact; CLP and MTV further significantly increased neutrophil immigration (Fig. 4) that was abolished in TLR4 null mice. Blocking WISP1 or integrin $\beta 5$ partially prevented the increase in the percentage of PMN induced in the two-hit model compared to combined CLP and MTV in mice receiving control IgG antibody.

We sought further evidence that MTV directly enhanced inflammation in the lungs of septic mice by measuring 

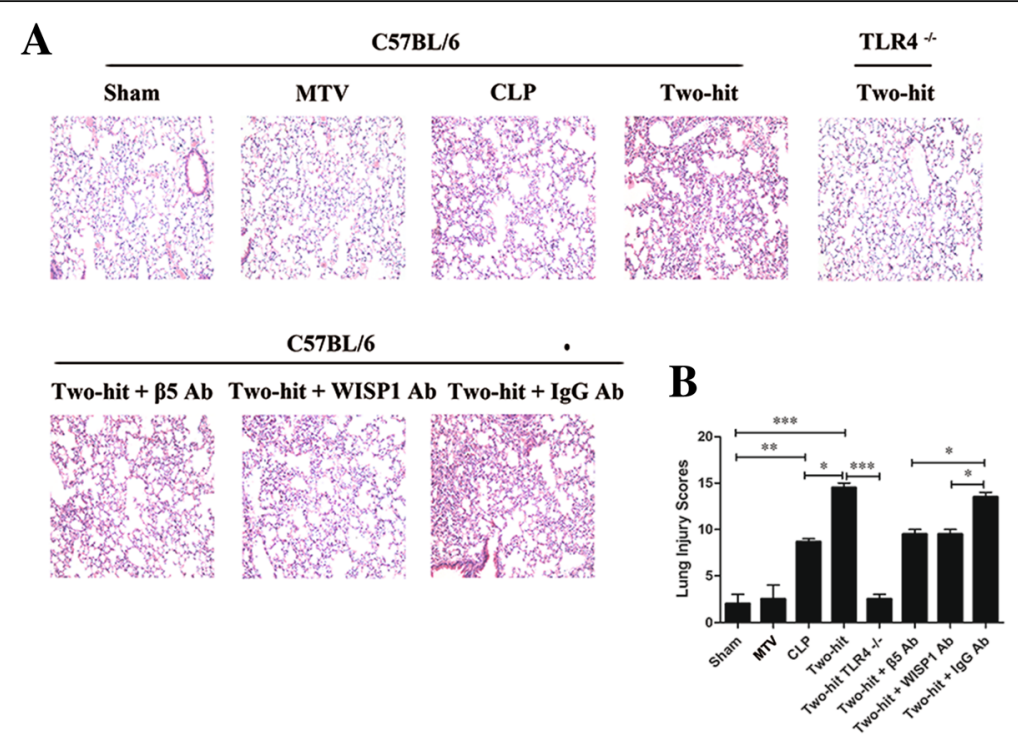

C

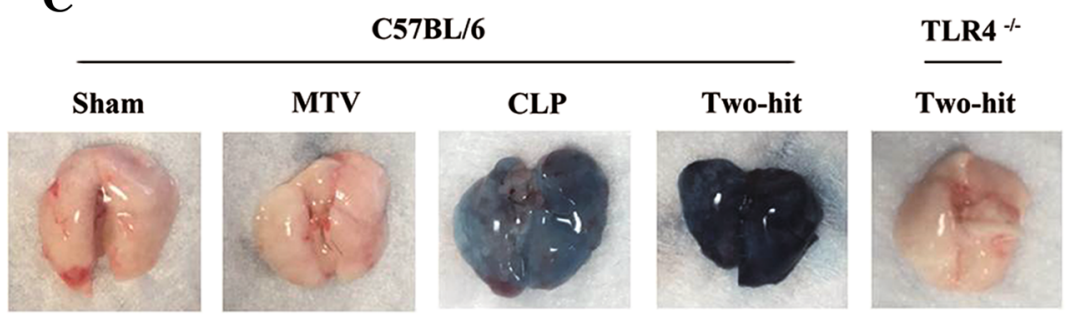

\section{C57BL/6}

Two-hit + 35 Ab Two-hit + WISP1 Ab Two-hit + IgG
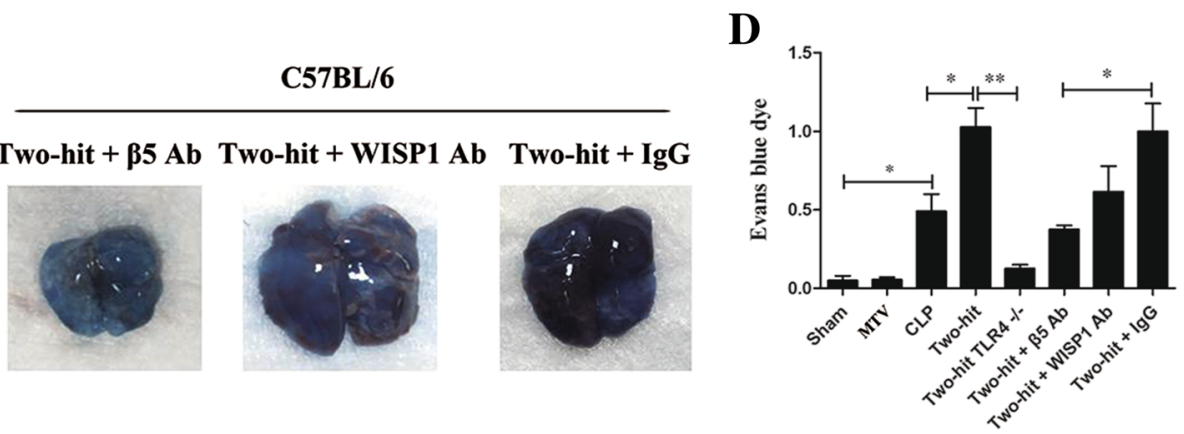

Fig. 1 MTV enhances CLP-induced lung damage via TLR4-dependent WISP1-integrin $\beta 5$ pathway. As shown in Additional file 1: Figure S1, mice lung tissue samples in eight mice groups were fixed and stained with hematoxylin-eosin for histological analysis (a) and lung injury score (b). Gross lung image in each group (c) and vascular permeability evaluated by Evans blue dye (d). Mice receiving combination of CLP + MTV (two-hit model) compared to mice subjected to CLP alone for $18 \mathrm{~h}$ or sham operation followed by $6 \mathrm{~h}$ of MTV. Two-hit model in wildtype mice compared to subgroup of $\mathrm{TLR4}^{-1-}$ mice or wildtype mice that received intratracheally neutralizing antibodies to either integrin $\beta 5$ ( $\beta 5$ Ab) or WISP1 (WISP1 Ab) or a control antibody (IgG Ab) during mechanical ventilation. ${ }^{*} P<0.05 ;{ }^{* *} P<0.01 ;{ }^{* *} P<0.001$. CLP cecal ligation and puncture, MTV moderate tidal ventilation, TLR4 toll-like receptor 4, WISP1 WNT1 inducible secreted protein

levels of activated JNK, p38 and ERK MAP kinase. Six hours of MTV had no effect on MAP kinase activation but significantly promoted MAP kinase activation in mice previously subjected to CLP (Additional file 3: Figure S3). TLR4 deletion prevented the increases in MAPK activation in CLP-treated and CLP + MTV-treated mice. Blocking
WISP1 or integrin $\beta 5$ also prevented the increase in MAP kinase phosphorylation induced by MTV in CLP mice.

To explore the mechanism of integrin $\beta 5$ upregulation by TLR4, we exposed peritoneal macrophages (PM) to LPS and found that ultrapure LPS induced a time and concentration-dependent increase in surface integrin $\beta 5$ 


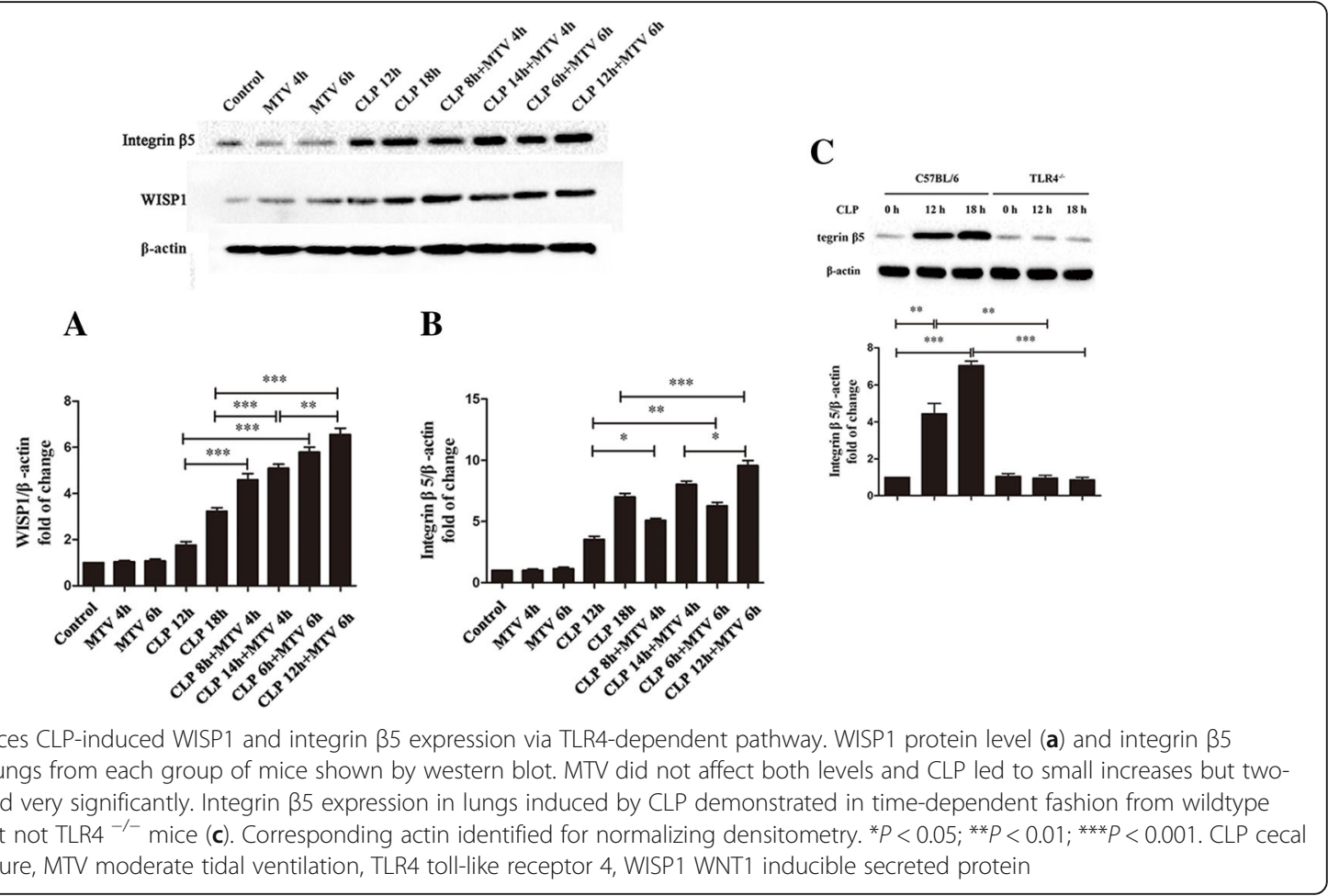

expression (Additional file 4: Figure S4). The increase in integrin $\beta 5$ expression was TLR4 and MyD88 dependent, but TRIF independent (Additional file 5: Figure S5). We also found that integrin $\beta 5$ upregulation by LPS was NF- $\mathrm{kB}$ dependent (Additional file 6: Figure S6).

LPS-induced increases in IL-6, TNF- $\alpha$, MIP-2 and MCP-1 in medium of isolated PM were evident within 4-10 $\mathrm{h}$ and the addition of rWISP1 induced further increases in all four mediators (Fig. 5). No increase in any of the mediators could be seen in PM from TLR4 ${ }^{-1-}$ mice. Suppression of integrin $\beta 5$ expression with siRNA (Additional file 7: Figure S7) prevented the WISP1-induced enhancement of LPS-induced IL-6, TNF- $\alpha$, MIP-2 and MCP-1 released by PM (Fig. 5).

\section{Discussion}

In the current study, MTV did not cause ALI, but exacerbated CLP-mediated increases in alveolar-capillary permeability and indices of pulmonary inflammation (histopathology, cytokines, chemokines, neutrophil influx and activation of MAPK) in wildtype mice: the effects of this two-hit model were completely abrogated in TLR4 null mutants and partially inhibited by neutralizing antibodies to either WISP1 or integrin $\beta 5$. In PM, activation of TLR4 led to an increase in integrin $\beta 5$ expression and rWISP1 increased LPS-induced cytokine release in PM that could be inhibited by silencing either TLR4 or integrin 35 . Collectively, these data show: that prolonged MTV ventilation exacerbates ALI caused by extrapulmonary sepsis; and an important positive feedback role for the WISP1-integrin $\beta 5$ pathway in TLR4-mediated exacerbations to this two-hit model.

Mechanical ventilation with high VT is well known to injure healthy lungs and a consensus from experimental and clinical conditions supports the hypothesis that mechanical ventilation can worsen injury in previously damaged lungs [1, 11, 29-31]. Although systemic [11] endotoxin interacts with mechanical ventilation in producing ALI [16], there is a lack of consensus from studies directed at identifying extrapulmonary bacterial sepsis as a sensitizing condition to VILI. CLP remains the gold standard of experimental polymicrobial sepsis [15] but ventilating rodents after CLP has produced equivocal results regarding sensitization to VILI $[9,18$, 19]. Nin et al. [16] reported that mechanical ventilation aggravated CLP-induced multiorgan dysfunction in rats but the investigators used prolonged CLP (24-48 h) and high VT $(35 \mathrm{ml} / \mathrm{kg})$. Others have used lower VT ventilation after CLP and did not observe worsening of lung injury [9]. Uematsu et al. [17] noted that high VT ventilation $(40 \mathrm{ml} / \mathrm{kg})$ after CLP increased mediator release but did not affect pulmonary function. Yehya et al. [18] showed that high VT $(30 \mathrm{ml} / \mathrm{kg})$ accelerated lung injury secondary to previous CLP in rats but the endpoints of injury (lung compliance, pulmonary edema, oxygenation and computed tomography of micro-CT scans) reached the same pathophysiology as from CLP alone. These authors highlighted subtleties in the degree of initial 


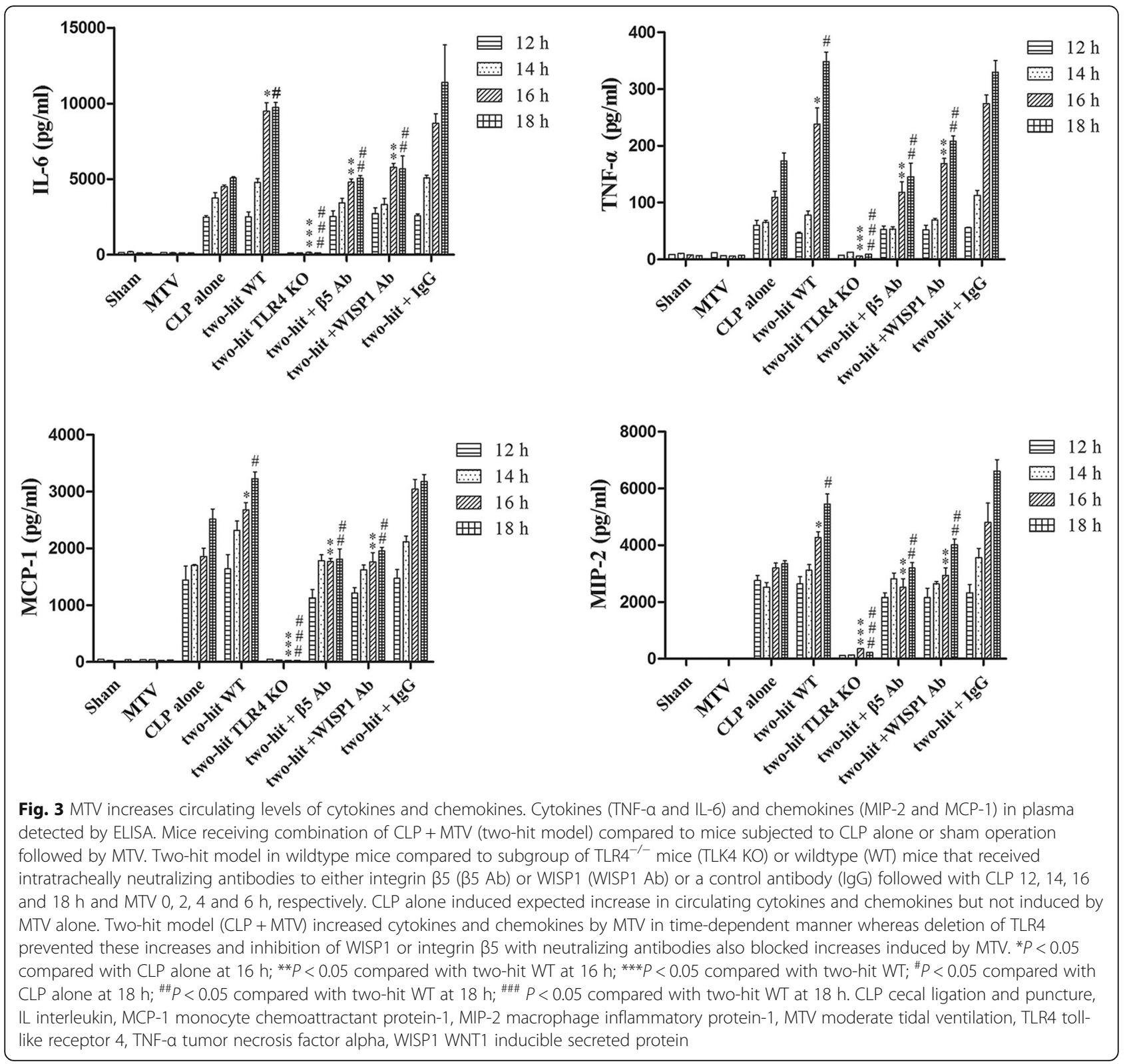

injury with CLP and the magnitude and duration of mechanical ventilation, and speculated that prolonged ventilation with lower VT may indeed enhance lung injury after CLP. In this regard, we unequivocally note that otherwise noninjurious MTV for a prolonged $(6 \mathrm{~h})$ time exacerbated underlying CLP-induced ALI. Indeed, whether CLP in itself causes ALI in mice is conjectural. Iskander et al. [32] clearly showed that pulmonary injury after CLP in mice cannot be considered the etiology of death in the acute phase. The authors did note that a severe model of sepsis with significant mortality could show signs of lung injury. We reported previously $[22,23,28]$ that the current model of CLP was associated with $80 \%$ mortality in $72 \mathrm{~h}$ and this presumably accounted for the modest but significant ALI noted at the earlier time period in the current study. Furthermore, we noted that $6 \mathrm{~h}$ of MTV $(10 \mathrm{ml} / \mathrm{kg})$ without PEEP was void of significant lung injury. In this regard, our model of effects of mechanical ventilation reproduces previous experience of lack of injury with MTV $(10 \mathrm{ml} / \mathrm{kg}$, zero PEEP) $[4,28]$, and was somewhat similar to the results from Hegeman et al. [33] who noted little evidence of ALI in mice after $5 \mathrm{~h}$ of mechanical ventilation with $7 \mathrm{ml} / \mathrm{kg}$ and $3 \mathrm{cmH}_{2} \mathrm{O}$ of PEEP or $5 \mathrm{~h}$ of $\mathrm{MV}$ with $15 \mathrm{ml} / \mathrm{kg}$ and zero PEEP. These authors did report VILI under both conditions at a longer time period (12 h) [33]. 


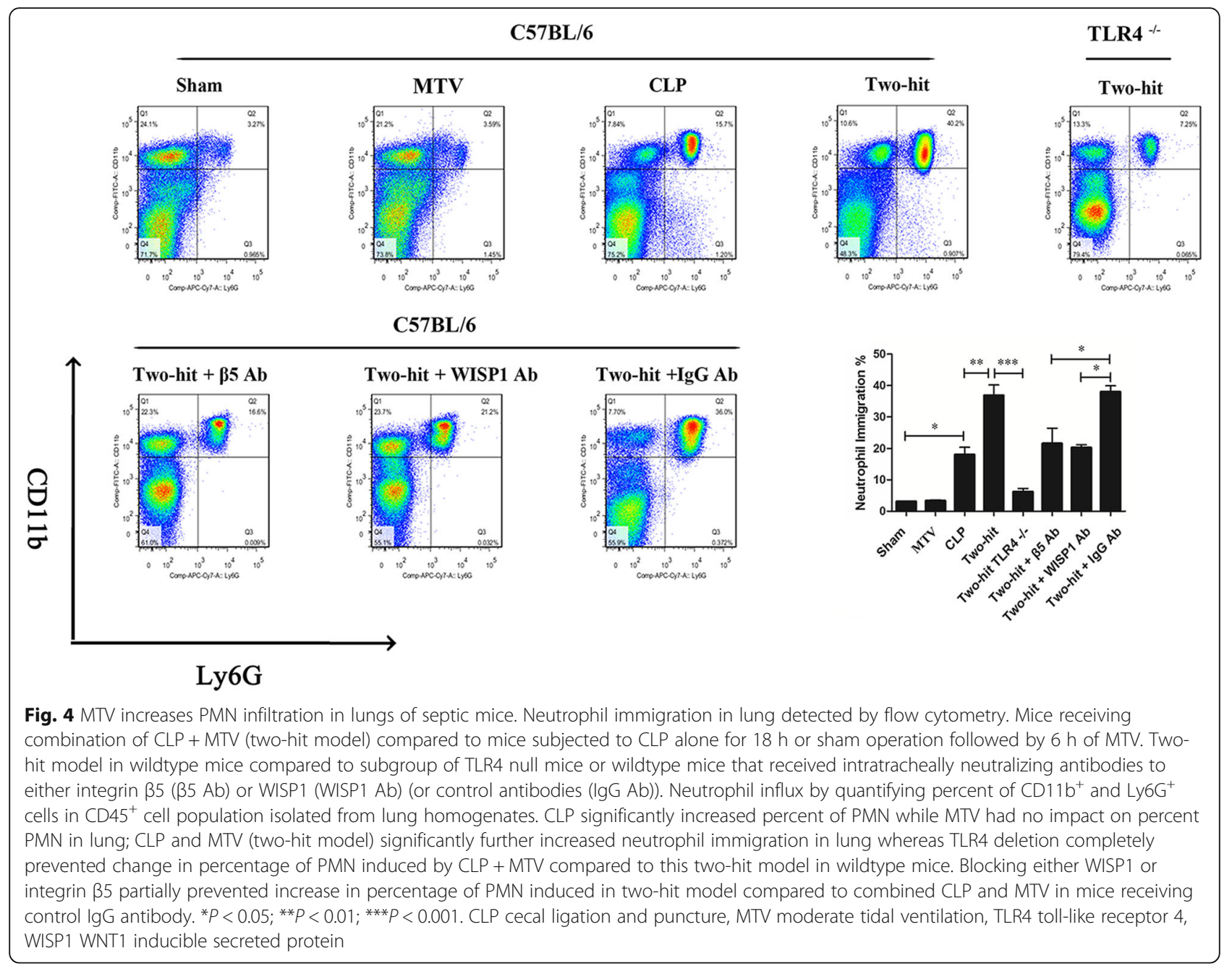

We $[21,34]$ and others $[5,35]$ have noted the important role of TLR4 in experimental VILI. We also noted $[22,23,28]$ that a considerable component of pathophysiology, inflammation and injury of CLP was due to TLR4 activation (and CD14). The injury, neutrophil sequestration and inflammation due to combined effects of CLP and MTV in the current study were all abrogated in TLR4 null mice.

WISP1 is a secreted matricellular protein involved in cell adhesion, migration, differentiation, proliferation and survival [36]. From an unbiased haplotype association mapping in inbred strains of mice, we identified WISP1 as a candidate gene associated with VILI [21]. We subsequently identified a role for WISP1 in CLP-induced ALI $[22,23]$. WISP1 was first noted in the lung to be a component of bleomycin-induced lung injury and fibrosis [37], and subsequently has been reported to be important in epithelial-mesenchymal transition [38], airway remodeling [39] and proliferation of fibroblasts in the context of lung fibrosis [40]. In-vitro mechanical stretch of type II epithelial cells activated innate immunity and increased WISP1 expression, providing fundamental support for its involvement in VILI [41]. We noted that intrapulmonary WISP1 is elevated in VILI [21], CLP [22, 23], combined poly(I:C) and mechanical ventilation [42], and in the current report in combined CLP and MTV; neutralizing antibodies to WISP1 partially reduced lung injury and inflammation in all of these conditions. The potential convergence of $\mathrm{WNT} / \beta$-catenin signaling and WISP1 adds to its importance in VILI [43] as well as WNT-mediated lung epithelial cell repair [44].

The mechanism by which WISP1 acts in CLP and/or VILI remains unclear. It appears, however, to be a modulator of TLR4-CD14 signaling and is known to signal through integrins [24]. WISP1 coimmunoprecipitated with active, glycosylated TLR4 in lungs of mice subjected to high VT ventilation and rWISP1 augmented LPS-induced TNF- $\alpha$ release in a TLR4-CD14-dependent fashion in PM [21]. The RGD peptide-sensitive response of intact mouse lungs to CLP and the coimmunoprecipitation of WISP1-integrin $\beta 6$ in lungs of these mice [23] 


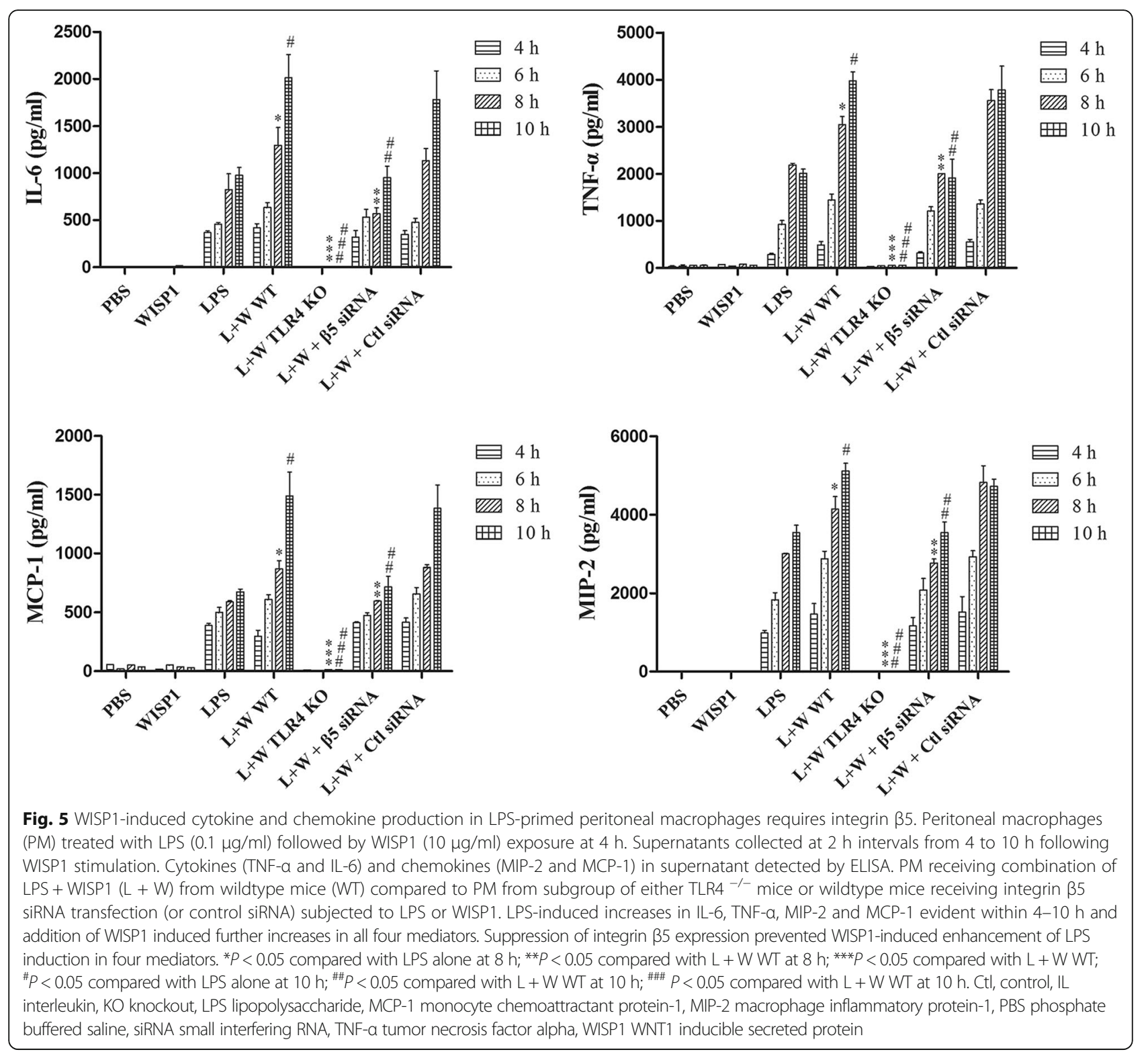

suggested the presence of the WISP1-integrin $\beta 6$ pathway in mediating TLR4-dependent inflammation and injury. We noted an obligatory role for integrin $\beta 3$ in WISP1-mediated release of TNF- $\alpha$ in PM [22] and an important role for integrin $\beta 3$ in polymicrobial sepsis and combined injury from poly $\mathrm{I}: \mathrm{C}$ instillation and mechanical ventilation [42]. In the current study we noted that siRNA to integrin $\beta 5$ reduced WISP1-mediated release of multiple cytokines in PM and integrin $\beta 5$ contributed to lung inflammation and injury with CLP and MTV. Identifying the precise integrin $\beta$ subunit involved in complex lung injury and signaling in isolated macrophages is complicated by: the multitude of $\beta$ subunits; the nondiscriminatory inhibition by RGD peptides; and the promiscuity of WISP1 regarding interactions with $\alpha \mathrm{V} \beta$ integrin subunit receptors [45]. We focused on the interaction of WISP1 and integrin $\beta 5$ because: others noted that WISP1 induces IL-6 production through integrin $\beta 5$ receptor in human synovial fibroblasts [46]; and although several integrins are important in ALI [25], integrin $\beta 5$ is a central regulator of increased permeability in VILI [26] and CLP [27].

We limited our phenotyping of lung injury to inflammation, alveolar-capillary permeability and histopathologic changes, and did not assess lung mechanics or evolution of changes in gas exchange. As such, fundamental issues of alveolar overdistension and physiologic consequences in the current study remain conjectural. It is noteworthy, however, that we recently reported [28] that low VT $(6 \mathrm{ml} / \mathrm{kg} ; 6 \mathrm{~h})$ mechanical ventilation was protective after 
CLP (6 h). We relied on neutralizing antibodies to assess the role of WISP1 and integrin $\beta 5$ in a two-hit model and partial effects noted in the study may have been secondary to incomplete deletion. For pragmatic reasons, we used PM as a surrogate for the likely cell of interest (alveolar macrophage) and future studies validating these observations with alveolar macrophages, a more challenging cell to isolate in sufficient number, are necessary.

\section{Conclusion}

In the current study, we provide evidence that mild lung injury secondary to extrapulmonary sepsis can sensitize intact mouse lung to subsequent prolonged MTV. This two-hit model is TLR4 sensitive and has important proinflammatory contributions from both WISP1 and integrin $\beta 5$. In isolated PM, we further defined the nature of WISP1 signaling and identified a requisite TLR4-dependent activation of integrin $\alpha_{\mathrm{V}} \beta 5$ and MyD88-NF-kB pathway inflammatory mediator biosynthesis. This two-hit model provides relevant new information regarding unresolved issues of a common risk factor for ARDS (systemic sepsis) and sensitization to often-used MTV.

\section{Additional files}

Additional file 1: Figure S1. Flow chart of two-hit animal model: CLP followed by MTV. Mice treated as Sham group (sham CLP and sham MTV), MTV group (sham CLP followed with 6-h MTV at $10 \mathrm{ml} / \mathrm{kg}$ ), CLP group (12-h CLP followed with spontaneous breathing-sham MTV) and two-hit group (12-h CLP followed with 6-h MTV). Two-hit model established by mild sepsis induced by cecal ligation and puncture (CLP) with a 22-gauge needle for $12 \mathrm{~h}$ followed by mechanical ventilation with moderate tidal volume at $10 \mathrm{ml} / \mathrm{kg}\left(\mathrm{MTV} ; 50 \% \mathrm{O}_{2}\right.$ ) and 150 breaths $/ \mathrm{min}$ for 2-6 h. Two-hit model in wildtype mice compared to subgroup of TLR4 null mice (TLR4 ${ }^{-/}$) or wildtype mice that received intratracheally neutralizing antibodies to either integrin $\beta 5$ ( $35 \mathrm{Ab}$ ) or WISP1 (WISP1 Ab) or a control antibody (lgG Ab) during mechanical ventilation (TIF 3849 kb)

Additional file 2: Figure S2. Schematic of experimental groups in peritoneal macrophages. Peritoneal macrophages (PM) obtained from wildtype, TLR $^{-1-}$ mice and treated with LPS $(0.1 \mu \mathrm{g} / \mathrm{ml})$ and/or siRNA to integrin $\beta 5$ followed by WISP1 $(10 \mu \mathrm{g} / \mathrm{ml})$ exposure at $4 \mathrm{~h}$. Supernatants collected at 2-h intervals from 4 to $10 \mathrm{~h}$ (TIF $2044 \mathrm{~kb}$ )

Additional file 3: Figure S3. MTV increases inflammatory signaling in lungs of mice after CLP. Western blot for activated (phosphorylated) p-JNK (A), p-p38 (B) and p-Erk (C) MAP kinase expression in lung homogenates. Mice receiving the combination of CLP + MTV (two-hit model) were compared to mice subjected to CLP alone for $18 \mathrm{~h}$ or sham operation followed by 6 h of MTV. Six hours of MTV alone had no effect on MAP kinase activation but significantly promoted MAP kinase activation in mice previously subjected to CLP, whereas TLR4 deletion prevented increases in MAPK activation in CLP-treated and CLP + MTV-treated mice and blocking WISP1 or integrin $\beta 5$ also prevented increase in MAP kinase phosphorylation induced by MTV in CLP mice. ${ }^{*} P<0.05$; ${ }^{* *} P<0.01$ (TIF $7656 \mathrm{~kb}$ )

Additional file 4: Figure S4. LPS-induced increase in integrin $\beta 5$ expression is time and concentration dependent. Integrin $\beta 5$ protein levels $(\mathbf{A}, \mathbf{C})$ and immunofluorescence for integrin $\beta 5$ (green) and nuclei with DAPI (blue) (B, D) in peritoneal macrophages (PM). Mouse PM isolated from C57BL/ 6 mice and stimulated with $\operatorname{LPS}(0,0.01,0.1,1,10 \mu \mathrm{g} / \mathrm{ml})$ in DMEM containing $10 \%$ FBS for $0-8 \mathrm{~h}$. LPS induced time and concentration-dependent increase in integrin $\beta 5$ protein levels and increase in surface integrin $\beta 5$ expression maximal at $6 \mathrm{~h}$. Corresponding actin identified for normalizing densitometry of integrin $\beta 5$ expression. ${ }^{*} P<0.01$ (TIF $1689 \mathrm{~kb}$ )

Additional file 5: Figure S5. Upregulation of integrin $\beta 5$ requires TLR4/ MyD88 signaling. Western blot for integrin $\beta 5$ protein $(\mathbf{A}, \mathbf{B})$ and immunostaining of integrin $\beta 5(\mathbf{C})$ in peritoneal macrophages (PM). Increase in integrin $\beta 5$ protein levels and its surface expression was TLR4 and MyD88 dependent (A), but TRIF independent (B). Mouse PM isolated from C57BL/6 (wildtype), TLR4 ${ }^{-/-}$, MyD88 ${ }^{-/-}$and TRIF ${ }^{-/-}$mice and stimulated with LPS $(0.1 \mu \mathrm{g} / \mathrm{ml})$ in DMEM containing 10\% FBS for $0-6 \mathrm{~h}$. Corresponding actin identified for normalizing densitometry. Immunofluorescence for integrin $\beta 5$ stained green while nuclei stained with DAPI (blue). Images acquired using EVOSfl fluorescence microscopy. ${ }^{*} P<0.05$; ${ }^{*} P<0.01$; ${ }^{* * *} P<0.001$ (TIF $4019 \mathrm{~kb}$ )

Additional file 6: Figure S6. Integrin $\beta 5$ upregulation by LPS is NF-KB dependent. Western blot for nuclear and cytoplasma NF-KB p65 (A) and immunostaining of NF-KB p65 (C) in peritoneal macrophages (PM) induced by LPS over time. Increase in integrin $\beta 5$ protein levels induced by LPS at $4.5 \mathrm{~h}$ significantly decreased by inhibitor of NF-KB signaling, IKK-NBD (B). ${ }^{*} P<0.05 ;{ }^{*} P<0.01 ;{ }^{* *} P<0.001$ (TIF $613 \mathrm{~kb}$ )

Additional file 7: Figure S7. siRNA to integrin $\beta 5$ suppressed LPSinduced increases in integrin $\beta 5$ levels in PM. Western blot for integrin $\beta 5$ levels in PM after treating with siRNA to integrin $\beta 5$ or control siRNA. Integrin $\beta 5$ siRNA dose-dependently suppressed LPS-induced increases in integrin $\beta 5$ levels compared to control siRNA. ${ }^{*} P<0.05$; ${ }^{*} P<0.01$; ***P $<0.001$ (TIF $4824 \mathrm{~kb}$ )

Additional file 8 Materials and Methods Eight to 10-week-old male C57BL/6 mice purchased from Jackson Laboratory. TLR4 ${ }^{-/-}$, MyD $88^{-/-}$, $\mathrm{TRIF}^{-1-}$ mice obtained from Dr Billiar's laboratory. All mice used were on a C57BL/ 6 background with appropriate backcrossing for respective knockouts. Transgenic male mice confirmed to be desired genotype via standard PCR-based techniques. Animal protocols approved by the Animal Care and Use Committee of the University of Pittsburgh and experiments performed in strict adherence to National Institutes of Health Guidelines for the Use of Laboratory Animals. Mice bred and housed in specific pathogen-free conditions with free access to food and water (DOCX $21 \mathrm{~kb})$

\section{Abbreviations}

ALI: Acute lung injury; ARDS: Acute respiratory distress syndrome; CLP: Cecal ligation and puncture; EBA: Evans blue albumin; LPS: Lipopolysaccharide; MTV: Moderate tidal ventilation; MyD88: Myeloid differentiation factor 88; PM: Peritoneal macrophages; PMN: Polymorphonuclear leukocyte; RGD peptide: Arg-Gly-Asp peptide; TLR4: Toll-like receptor 4; TRIF: TIR-domaincontaining adaptor inducing interferon beta; VILI: Ventilator-induced lung injury; WISP1: WNT1 inducible secreted protein

\section{Acknowledgements}

The authors thank Jing Xu, Li Xu, Zhengzheng Yan, Xubo Wu and Hong Liao for technical assistance.

\section{Funding}

This work was supported by National Institute of Health grants (R01-GM-50441 to TRB and R01-GM-108639 to L-MZ) for the design of the study, collection and writing the manuscript, and by the National Natural Science Foundation (81270135 to QL and 81772114 to QL) for analysis and interpretation of data.

\section{Availability of data and materials}

The datasets generated and/or analyzed during the current study are available in the Dr Billiar laboratory of University of Pittsburgh, and the datasets are available from the corresponding author on request.

\section{Authors' contributions}

$X b D, Y T, S q J, Z x C, T I L, T R B, B R P, Q L$ and L-MZ contributed to study concepts and design. XbD, YT, SqJ, ZxC and TIL collected data. XbD, TRB, BRP, QL and L-MZ wrote the first version of the manuscript. XbD, SqJ, TIL, QL, L-M.Z, BRP and TRB performed data analysis and interpretation. XbD, TY, SqJ, ZxC and TIL performed statistical analysis. XbD, YT, SqJ, ZxC, TIL, TRB, BRP, QL and 
L-MZ contributed to manuscript preparation. XbD, YT, SqJ, ZxC, TIL, TRB, BRP, $\mathrm{QL}$ and L-MZ contributed to manuscript revision. All authors read and approved the final version of the manuscript.

\section{Ethics approval}

Animal protocols were approved by the Animal Care and Use Committee of the University of Pittsburgh and experiments were performed in strict adherence to the National Institutes of Health Guidelines for the Use of Laboratory Animals.

\section{Consent for publication}

Not applicable.

\section{Competing interests}

The authors declare that they have no competing interests.

\section{Publisher's Note}

Springer Nature remains neutral with regard to jurisdictional claims in published maps and institutional affiliations.

\section{Author details}

'Department of Anesthesiology, East Hospital, Tongji University School of Medicine, 150 Jimo Road, Pudong, Shanghai, China. ${ }^{2}$ Department of Anesthesiology, Xiangya 3rd Hospital, Central South University, Hunan, China. ${ }^{3}$ Department of Surgery, University of Pittsburgh School of Medicine, Pittsburgh, PA, USA. ${ }^{4}$ Department of Environmental and Occupational Health, University of Pittsburgh Graduate School Public Health, Pittsburgh, PA, USA. ${ }^{5}$ Department of Anesthesiology, University of Pittsburgh School of Medicine, 200 Lothrop St. UPMC MUH N467, Pittsburgh 15213, PA, USA. ${ }^{6}$ Department of Anesthesiology, Renji Hospital, Shanghai Jiaotong University School of Medicine, Shanghai, China. ${ }^{7}$ Department of Anesthesiology, Cancer Hospital Chinese Academy of Medical Sciences, Shenzhen, China.

\section{Received: 2 January 2018 Accepted: 15 October 2018}

\section{Published online: 16 November 2018}

\section{References}

1. Slutsky AS, Ranieri VM. Ventilator-induced lung injury. N Engl J Med. 2013; 369:2126-36.

2. Dhanireddy S, Altemeier WA, Matute-Bello G, O'Mahony DS, Glenny RW, Martin TR, et al. Mechanical ventilation induces inflammation, lung injury, and extra-pulmonary organ dysfunction in experimental pneumonia. Lab Investig. 2006:86:790-9.

3. Muller-Redetzky HC, Will D, Hellwig K, Kummer W, Tschernig T, Pfeil U, et al. Mechanical ventilation drives pneumococcal pneumonia into lung injury and sepsis in mice: protection by adrenomedullin. Crit Care. 2014;18:R73.

4. Altemeier WA, Matute-Bello G, Gharib SA, Glenny RW, Martin TR, Liles WC. Modulation of lipopolysaccharide-induced gene transcription and promotion of lung injury by mechanical ventilation. J Immunol. 2005;175:3369-76

5. Hu G, Malik AB, Minshall RD. Toll-like receptor 4 mediates neutrophil sequestration and lung injury induced by endotoxin and hyperinflation. Crit Care Med. 2010;38:194-201.

6. Ding N, Wang F, Xiao H, Xu L, She S. Mechanical ventilation enhances HMGB1 expression in an LPS-induced lung injury model. PLoS One. 2013;8(9):e74633.

7. Rentsendorj O, Damarla M, Aggarwal NR, Choi JY, Johnston L, D'Alessio FR, et al. Knockdown of lung phosphodiesterase 2A attenuates alveolar inflammation and protein leak in a two-hit mouse model of acute lung injury. Am J Physiol Lung Cell Mol Physiol. 2011;301:L161-70.

8. Frank JA, Gutierrez JA, Jones KD, Allen L, Dobbs L, Matthay MA. Low tidal volume reduces epithelial and endothelial injury in acid-injured rat lungs. Am J Respir Crit Care Med. 2002;165:242-9.

9. Kuiper JW, Plotz FB, Groeneveld AJ, Haitsma JJ, Jothy S, Vaschetto R, et al. High tidal volume mechanical ventilation-induced lung injury in rats is greater after acid instillation than after sepsis-induced acute lung injury, but does not increase systemic inflammation: an experimental study. BMC Anesthesiol. 2011;11:26.

10. Makena PS, Luellen CL, Balazs L, Ghosh MC, Parthasarathi K, Waters CM, et al. Preexposure to hyperoxia causes increased lung injury and epithelial apoptosis in mice ventilated with high tidal volumes. Am J Physiol Lung Cell Mol Physiol. 2010;299:1467-76.

11. Altemeier WA, Matute-Bello G, Frevert CW, Kawata Y, Kajikawa O, Martin TR, et al. Mechanical ventilation with moderate tidal volumes synergistically increases lung cytokine response to systemic endotoxin. Am J Physiol Lung Cell Mol Physiol. 2004;287:L533-42.

12. Bregeon F, Delpierre S, Chetaille B, Kajikawa O, Martin TR, Autillo-Touati A, et al. Mechanical ventilation affects lung function and cytokine production in an experimental model of endotoxemia. Anesthesiology. 2005;102:331-9.

13. Chaudry $I H$, Wichterman KA, Baue AE. Effect of sepsis on tissue adenine nucleotide levels. Surgery. 1979;85:205-11.

14. Villar J, Ribeiro SP, Mullen JB, Kuliszewski M, Post M, Slutsky AS. Induction of the heat shock response reduces mortality rate and organ damage in a sepsis-induced acute lung injury model. Crit Care Med. 1994;22:914-21.

15. Dejager L, Pinheiro I, Dejonckheere E, Libert C. Cecal ligation and puncture: the gold standard model for polymicrobial sepsis? Trends Microbiol. 2011:19:198-208.

16. Nin N, Lorente JA, Fernandez-Segoviano P, De Paula M, Ferruelo A, Esteban A. High-tidal volume ventilation aggravates sepsis-induced multiorgan dysfunction in a dexamethasone-inhibitable manner. Shock. 2009;31:429-34.

17. Uematsu S, Engelberts D, Peltekova V, Otulakowski G, Post M, Kavanagh BP. Dissociation of inflammatory mediators and function: experimental lung injury in nonpulmonary sepsis. Crit Care Med. 2013;41:151-8.

18. Yehya N, Xin Y, Oquendo Y, Cereda M, Rizi RR, Margulies SS. Cecal ligation and puncture accelerates development of ventilator-induced lung injury. Am J Physiol Lung Cell Mol Physiol. 2015;308:L443-51.

19. Nakamura T, Malloy J, McCaig L, Yao LJ, Joseph M, Lewis J, et al. Mechanical ventilation of isolated septic rat lungs: effects on surfactant and inflammatory cytokines. J Appl Physiol (1985). 2001;91:811-20.

20. Villar J, Cabrera N, Casula M, Flores C, Valladares F, Muros M, et al. Mechanical ventilation modulates Toll-like receptor signaling pathway in a sepsis-induced lung injury model. Intensive Care Med. 2010;36:1049-57.

21. Li HH, Li Q, Liu P, Liu Y, Li J, Wasserloos K, et al. WNT1-inducible signaling pathway protein 1 contributes to ventilator-induced lung injury. Am J Respir Cell Mol Biol. 2012;47:528-35.

22. Chen Z, Ding $X$, Jin S, Pitt B, Zhang L, Billiar T, et al. WISP1-alphavbeta3 integrin signaling positively regulates TLR-triggered inflammation response in sepsis induced lung injury. Sci Rep. 2016;6:28841.

23. Ding $X$, Wang $X$, Zhao $X$, Jin S, Tong $Y$, Ren $H$, et al. RGD peptides protects against acute lung injury in septic mice through Wisp1-integrin beta6 pathway inhibition. Shock. 2015;43(4):352-60.

24. Leask A, Abraham DJ. All in the CCN family: essential matricellular signaling modulators emerge from the bunker. J Cell Sci. 2006;119:4803-10.

25. Sheppard D. Modulation of acute lung injury by integrins. Proc Am Thorac Soc 2012:9:126-9.

26. Su G, Hodnett M, Wu N, Atakilit A, Kosinski C, Godzich M, et al. Integrin alphavbeta5 regulates lung vascular permeability and pulmonary endothelial barrier function. Am J Respir Cell Mol Biol. 2007;36:377-86.

27. Su G, Atakilit A, Li JT, Wu N, Luong J, Chen R, et al. Effective treatment of mouse sepsis with an inhibitory antibody targeting integrin alphavbeta5. Crit Care Med. 2013:41:546-53.

28. Ding $X$, Jin S, Shao Z, Xu L, Yu Z, Tong Y, Chen Z, Turnquist H, Pitt BR, Billiar TR, Zhang LM, Li Q. Shock. 2018. https://doi.org/10.1097/SHK. 0000000000001260. [Epub ahead of print]. PMID:30192340.

29. Curley GF, Laffey JG, Zhang H, Slutsky AS. Biotrauma and ventilator-induced lung injury: clinical implications. Chest. 2016;150:1109-17.

30. Gattinoni L, Protti A, Caironi P, Carlesso E. Ventilator-induced lung injury: the anatomical and physiological framework. Crit Care Med. 2010;38:S539-48.

31. Matthay MA, Bhattacharya S, Gaver D, Ware LB, Lim LH, Syrkina O, et al. Ventilator-induced lung injury: in vivo and in vitro mechanisms. Am J Physiol Lung Cell Mol Physiol. 2002;283:L678-82.

32. Iskander KN, Craciun FL, Stepien DM, Duffy ER, Kim J, Moitra R, et al. Cecal ligation and puncture-induced murine sepsis does not cause lung injury. Crit Care Med. 2013:41:159-70

33. Hegeman MA, Hemmes SN, Kuipers MT, Bos LD, Jongsma G, Roelofs JJ, et al. The extent of ventilator-induced lung injury in mice partly depends on duration of mechanical ventilation. Crit Care Res Pract. 2013:2013:435236

34. Li H, Su X, Yan X, Wasserloos K, Chao W, Kaynar AM, et al. Toll-like receptor 4-myeloid differentiation factor 88 signaling contributes to ventilatorinduced lung injury in mice. Anesthesiology. 2010;113:619-29. 
35. Vaneker M, Joosten LA, Heunks LM, Snijdelaar DG, Halbertsma FJ, van Egmond J, et al. Low-tidal-volume mechanical ventilation induces a toll-like receptor 4-dependent inflammatory response in healthy mice. Anesthesiology. 2008;109:465-72

36. Brigstock DR. The CCN family: a new stimulus package. J Endocrinol. 2003;178:169-75.

37. Konigshoff M, Kramer M, Balsara N, Wilhelm J, Amarie OV, Jahn A, et al. WNT1-inducible signaling protein-1 mediates pulmonary fibrosis in mice and is upregulated in humans with idiopathic pulmonary fibrosis. J Clin Invest. 2009;119:772-87.

38. Berschneider B, Konigshoff M. WNT1 inducible signaling pathway protein 1 (WISP1): a novel mediator linking development and disease. Int J Biochem Cell Biol. 2011;43:306-9.

39. Yang M, Du Y, Xu Z, Jiang Y. Functional effects of WNT1-inducible signaling pathway protein-1 on bronchial smooth muscle cell migration and proliferation in OVA-induced airway remodeling. Inflammation. 2016:39:16-29.

40. Klee S, Lehmann M, Wagner DE, Baarsma HA, Konigshoff M. WISP1 mediates IL-6-dependent proliferation in primary human lung fibroblasts. Sci Rep. 2016;6:20547.

41. Heise RL, Stober V, Cheluvaraju C, Hollingsworth JW, Garantziotis S. Mechanical stretch induces epithelial-mesenchymal transition in alveolar epithelia via hyaluronan activation of innate immunity. J Biol Chem. 2011; 286:14735-44.

42. Jin $S$, Chen Z, Ding X, Zhao X, Jiang X, Tong Y, et al. Mechanical ventilation augments poly(l:C)induced lung injury via a wisp1-integrin beta3 dependent pathway in mice. Mol Med. 2016;22:54-63.

43. Villar J, Cabrera NE, Casula M, Valladares F, Flores C, Lopez-Aguilar J, Blanch L, Zhang H, Kacmarek RM, Slutsky AS. WNT/beta-catenin signaling is modulated by mechanical ventilation in an experimental model of acute lung injury. Intensive Care Med. 2011;37:1201-9.

44. Zemans RL, et al. Role of $\beta$-catenin-regulated CCN matricullar proteins in epithelial repair after inflammatory lung injury. Am J Physiol. 2013;304:L415-27.

45. Chen CC, Lau LF. Functions and mechanisms of action of CCN matricellular proteins. Int J Biochem Cell Biol. 2009;41:771-83.

46. Hou CH, Tang CH, Hsu CJ, Hou SM, Liu JF. CCN4 induces IL-6 production through al phavbeta5 receptor, PI3K, Akt, and NF-kappaB singling pathway in human synovial fibroblasts. Arthritis Res Ther. 2013;15:R19.

Ready to submit your research? Choose BMC and benefit from:

- fast, convenient online submission

- thorough peer review by experienced researchers in your field

- rapid publication on acceptance

- support for research data, including large and complex data types

- gold Open Access which fosters wider collaboration and increased citations

- maximum visibility for your research: over $100 \mathrm{M}$ website views per year

At $\mathrm{BMC}$, research is always in progress.

Learn more biomedcentral.com/submissions 